Tropical Journal of Pharmaceutical Research February 2012; 11 (1): 75-83

(C) Pharmacotherapy Group,

Faculty of Pharmacy, University of Benin

Benin City, 300001 Nigeria.

All rights reserved.

Available online at http://www.tjpr.org

Research Article

http://dx.doi.org/10.4314/tjpr.v11i1.10

\title{
Effect of Manasamitra vatakam, an Ayurvedic Formulation, on Aluminium-Induced Neurotoxicity in Rats
}

\author{
SV Thirunavukkarasu ${ }^{1,2 \star}$, Lokesh Upadhyay ${ }^{2}$ and S \\ Venkataraman ${ }^{1,3}$ \\ ${ }^{1}$ Department of Pharmacology, C.L. Baid Metha College of Pharmacy and Research Foundation, ${ }^{2}$ CARISM, Division \\ of Biochemistry, SASTRA University, Tamilnadu, India.
}

\begin{abstract}
Purpose: To investigate the effect of Manasamitra vatakam (MMV), an Ayurvedic formulation, on aluminium (Al)-induced neurotoxicity in rats.

Methods: Wistar rats were selected for the present study and were divided into four groups of six animals each. Group I (control) received tap water while group II received aluminium chloride $\left(\mathrm{AlCl}_{3}, 100\right.$ $\mathrm{mg} / \mathrm{kg} /$ day). Group III was treated with concurrently Al chloride (100 mg/kg/day) and MMV drug (100 $\mathrm{mg} / \mathrm{kg} /$ day). Group IV were administered MMV (100 mg/kg/day) for 90 days. Behavioral tests were performed on the rats during the experiment. At the end of the experiment various biochemical, neurochemical and histopathological histopathological was assessments were also carried out on the blood and brain of the rats.

Results: Following MMV treatment, there was a significant recovery in the performance of the radial maze and muscle grip strength of the rats, as well as the levels of deoxyribonucleic acid (DNA), ribonucleic acid (RNA), and acetylcholinestrase (AChE) in different parts of the rat's brain. The neuroprotective efficacy of MMV was supported by histopathological observations. Furthermore, MMV afforded protection against oxidative damage in the rats.

Conclusion: MMV prevents Al-induced toxicity in peripheral as well as in central nervous systems of rats. Therefore, further studies are required to ascertain its usefulness in humans.
\end{abstract}

Keywords: Rat brain, Aluminium chloride, Behavioral studies, Neurotoxicity, Manasamitra vatakam. 


\section{INTRODUCTION}

Aluminium metal (Al) is ubiquitous in the environment and may be linked to some diseases such as Alzheimer's disease, dementia and Parkinsonism. The daily intake of aluminium is estimated to be approximately $10-20 \mathrm{mg}$ from cooking utensils, food additives and medicines such as, antacids or deodorants [1]. Since a variety of biomolecules are able to bind aluminium, and it can displace other biological cations (such as calcium and magnesium) from their binding sites, almost every metabolic pathway is a potential target for the adverse effects of aluminium.

Strong et al [2] reported that $\mathrm{Al}^{3+}$ exposure cause impairments in glucose utilization, agonist-stimulated inositol phosphate accumulation. Aluminium salts may bind to DNA and RNA, may inhibit the activity of enzymes such as hexokinase, alkaline phosphatases, and phosphodiesterase [3]. It is known to enhance the peroxidative damage of lipids and decreases the antioxidant status in different parts of the rat brain. On the other hand, various natural antioxidants have been used as neuroprotective drugs which may increase the antioxidant status and thus maintain the proper functioning of brain, however, the detail mechanism of action of these drugs is not known. Manasamitra vatakam (MMV) is an herbo mineral drug used in India's Ayurvedic system of medicines for treating cognitive deficits. We previously reported the presence of phytoconstituents such as alkaloids, steroids, protein, tannins, phenols, flavanoids, saponins, amino acid, glycosides in the MMV. We also observed that MMV could affect the synthesis and release of a specific neurotransmitter enzyme, acetyl cholinesterase [4] as well as influenced various antioxidants parameters and showed good free radical scavenging activities [4]. However, the detailed mechanism of action as well as the neuroprotective effect of $M M V$ are not yet known. Therefore, the objective of this study was to investigate the neuro- protective effect of $M M V$ against Al-induced neurotoxicity and also to determine the relationship between molecular changes in rat brain and behavioral pattern in Al- treated rats.

\section{EXPERIMENTAL}

\section{Chemicals}

Aluminium chloride was purchased from Merck, Chennai, India. Tritonx-100 solution was purchased from Sigma-Aldrich Pvt Ltd., Bangalore, India. Standard pellet diet was obtained from Hindustan Lever, Bangalore, India. All other chemicals were purchased from Sisco Research Laboratories Pvt. Ltd, India.

\section{Test drug}

The Ayurvedic proprietary formulation, Manasamitra Vatakam (MMV) was obtained from Kotakkal arya vidya sala, Kerala, India. It was dissolved in distilled water and used for the animal studies.

\section{Animals}

Male Wistar albino rats $(200-220 \mathrm{~g})$ were housed in clean polypropylene cages and maintained at the room temperature $23-25^{\circ} \mathrm{C}$ with alternate $12 \mathrm{~h}$ light and dark cycles. The animals were fed on standard pellet diet and drinking water ad libitum. All procedures were carried out in accordance with the guidelines for care and use of laboratory animals. The protocols were approved by the institutional animal ethical committee (ref no. 14/18/IAEC/24/07/07) of C.L. Baid Metha College of Pharmacy (Chennai, India).

\section{Acute toxicity study}

Acute toxicity study was conducted according to Organization for Economic Cooperation and Development (OECD) guidelines (no. 423). Three mice (aged $5-6$ weeks and weighing $25-30 \mathrm{~g}$ ) were selected for the study. A single high dose of MMV $(2,000$ 
$\mathrm{mg} / \mathrm{kg}$ body weight was given orally to each animal. The animals were observed for $1 \mathrm{~h}$ continuously for any mortality or gross behavioral changes, then hourly for $4 \mathrm{~h}$ and thereafter, after every $24 \mathrm{~h}$ for up to 15 days [5].

\section{Experimental design}

The rats were divided into four groups of six animals each. Group I served as control and received the tap water while group II received aluminium chloride (100 mg/kg / day) dissolved in drinking water. Group III was treated simultaneously with aluminium chloride (100 mg/kg /day) and MMV (100 $\mathrm{mg} / \mathrm{kg}$ ). Group IV was administered only MMV (100 mg/kg). MMV and aluminium chloride (Al) were administered orally for 90 days except for group I. The animals were weighed twice a month and behavioral observations were recorded before and at the end of the experiment.

\section{Behavioral assessment}

\section{Radial arm maze test}

Radial maze is used to evaluate working memory in animals and cognitive tasks as comprehension, learning and reasoning. Each arm $(50 \times 12 \mathrm{~cm})$ of the eight arms radial maze extends from an octagonally shaped central hub of $30 \mathrm{~cm}$ diameter. The platform remains elevated up to $40 \mathrm{~cm}$ above the floor and small black plastic cups can be mounted at the end of each arm as containers for food. The trial is considered complete when the rats visit all eight arms or spends $10 \mathrm{~min}$ in the maze. Entry into an arm which the rat had not previously visited is recorded as a correct response and re-entry is counted as an error. The percentage of successful rats was calculated based on the total running time divided by the total number of choices to give the running time [6].

\section{Rota-rod test}

The effect of aluminium as well as $M M V$ treatment on muscle performance was evaluated using Rota-rod (Techno) test. All the rats were given two initial training trials of $300 \mathrm{~s}$, approximately $10 \mathrm{~min}$ apart, to maintain posture on the Rota-rod $(3 \mathrm{~cm}$ in diameter and rotating at a constant 20 $\mathrm{rev} / \mathrm{min}$ ). After the initial training trials, a baseline trial of $120 \mathrm{~s}$ was conducted. The time each animal remained on the rota-rod was recorded. The animals that did not fall off the Rota-rod were given a maximum score of $120 \mathrm{~s}[6]$.

\section{Biochemical assessment}

Blood samples were collected from each animal by retro-orbital sinus puncture at the end of experiment. The blood samples were centrifuged at $4000 \mathrm{rpm}$ for $5 \mathrm{~min}$ and the serum separated was stored at $-20{ }^{\circ} \mathrm{C}$ for evaluation of plasma glucose, Alkaline phosphatase (ALP), Serum glutamyloxaloacetate transaminase (SGOT), Serum glutamyl pyruvate transaminase (SGPT) and glucose were assessed using an autoanalyser (Biosystem 250).

The rats were sacrificed by cervical dislocation, the brain of each rat removed, immediately washed well with ice-cold saline to remove blood and stored at $-80{ }^{\circ} \mathrm{C}$ pending determination of biochemical parameters. The hippocampus and cerebral cortex were micro-dissected following the technique of Paxinos and Watson [7]. The left and right cerebral cortex of the brain of one rat was pooled to make one sample. A total of $10 \%$ homogenate was prepared using phosphate buffer $(0.1 \mathrm{M}, \mathrm{pH} 7.4)$ containing $1 \mathrm{mmol}$ ethylene diamine-tetra-acetic acid (EDTA), $0.25 \mathrm{M}$ sucrose, $10 \mathrm{mM}$ potassium chloride $(\mathrm{KCl})$ and $1 \mathrm{mM}$ phenyl methyl sulfonyl fluoride (PMSF) with a PotterElvehijem type homogenizer fitted with a teflon plunger, which was centrifuged at 800 $\mathrm{g}$ for $5 \mathrm{~min}$ at $4{ }^{\circ} \mathrm{C}$ in an IEC020 refrigerated centrifuge to yield the supernatant. The 
supernatant were used for the estimation of acetyl cholinestrase (AChE). The remaining supernatant was again centrifuged at 12,365 $\mathrm{g}$ for $15 \mathrm{~min}$ at $4{ }^{\circ} \mathrm{C}$ to obtain supernatant, which was used for the determination of brain levels of DNA and RNA.

\section{DNA and RNA assays}

Both total tissue DNA and RNA were separately extracted and assayed according to the method described by Sambrook et al [8]. and expressed in $\mathrm{mg} \mathrm{DNA} / \mathrm{g}$ tissue and $\mathrm{mg} \mathrm{RNA/g} \mathrm{tissue,} \mathrm{respectively.}$

\section{Evaluation of tissue acetyl cholinesterase (AChE)}

The acetylcholinesterase activity of rat brain tissue was determined by the method of Ellman et al [8]. An aliquot of the brain homogenate $(0.4 \mathrm{ml}$ obtained earlier was added to a cuvette containing $2.6 \mathrm{ml}$ of phosphate buffer ( $\mathrm{pH} 8.0,0.1 \mathrm{M}), 100 \mu \mathrm{l}$ of 2,4 dithionitrobenzene (DTNB) reagent was added to the cuvette followed by the addition of $20 \mu \mathrm{l}$ of acetylthiocholine iodide (AChl). Thiocholine reacted with DTNB reagent to produce a yellow color which was read spectrophotometrically at $412 \mathrm{~nm}$.

\section{Histopathological studies}

Histopathological evaluation was performed by the method of Nakayama et al [10]. The brain hippocampus of each animal was fixed with $10 \%$ formalin and further embedded in paraffin with wax. The blocks were processed for sectioning; the sections were then stained with haematoxylin and eosin as nuclear and cytoplasmic stains, respectively. Pathological changes, if any, were viewed under light microscope and recorded.

\section{Statistical analysis}

Statistical analysis was carried out using Graph Pad Prism software (version 4.03). One-way ANOVA was applied to process the data, followed by Newman-Keuls multiple comparison test. The data are presented as mean \pm SEM. The level of statistical significance was set at $p \leq 0.001$.

\section{RESULTS}

\section{Effect of Al chloride on mice behavioral characteristics}

When the mice were treated with $M M V$ up to $2000 \mathrm{mg} / \mathrm{kg}$ p.o. there was neither mortality nor any sign of gross behavioral changes after $48 \mathrm{~h}$, and 15 days. However, it was observed that the numbers of entries into radial arms of the rats increased in Al-treated rats, and the animals also spent less time in each radial arm of the apparatus, compared with the normal control. On the other hand, in groups III and IV the behavioural characteristics of learning and reasoning increased (Figure 1).

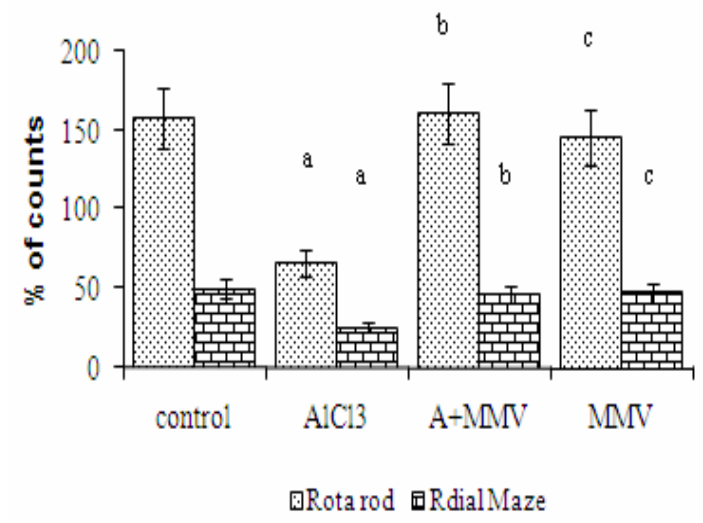

Figure 1: Effect of $M M V$ on behavioural characteristics (mean \pm SEM), assessed by Rota rod and Radial Maze analysis; ${ }^{a} p<0.001, \mathrm{AlCl}_{3}$ group compared with control group; ${ }^{b} p<0.001$, $M M V+\mathrm{AICl}_{3}$ group compared with aluminiumtreated group; ${ }^{\mathrm{C}}$ not significant $(p<0.001), M M V$ treated group compared with control

A significant decrease $(p<0.001)$ in muscle strength and locomotor activities was observed in Al-exposed rats compared with normal control. On the other hand, significant improvement in the muscle strength and muscle grip occurred in $M M V$-treated rats compared with Al-treated rats (Figure 1). 


\section{Biochemical parameters}

Figure 2 shows the effect of MMV on plasma parameters. Oral administration of $\mathrm{Al}(100 \mathrm{mg}$ $/ \mathrm{kg})$ for 90 days significantly $(p<0.001)$ increased plasma glucose, ALP, SGOT and SGPT whereas co-administration of $M M V$ with Al significantly $(p<0.001)$ decreased the levels of these parameters in rats. There was no significant alteration in plasma glucose, ALP, SGOT and SGPT when compared with normal control and rats treated with $M M V$ alone.

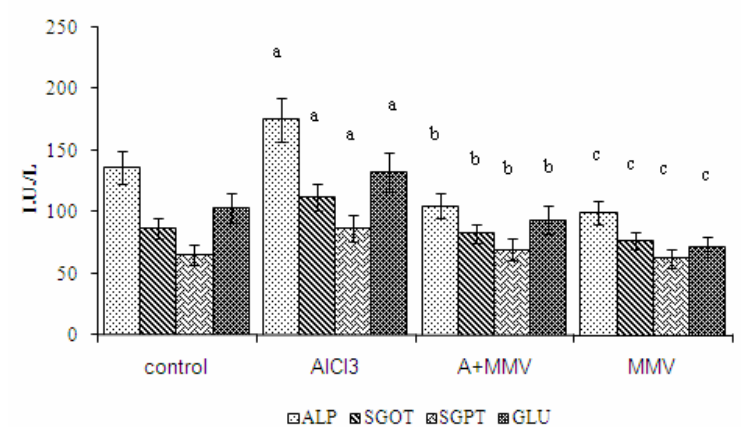

Figure 2: Effect of MMV on biochemical parameters (mean \pm SEM) in Al- treated rats.

a $p \leq 0.001, \mathrm{AlCl}_{3}$ group compared with control group; ${ }^{\mathrm{b}} p \leq 0.001, M M V+\mathrm{AlCl}_{3}$ group compared with aluminium-treated group; ${ }^{c}$ not significant $(p$ $\leq 0.001) M M V$ treated group versus control

The effect of MMV on DNA and RNA levels in blood and brain tissues are shown in Figures 3 and 4. DNA and RNA significantly decreased in Al-treated rats compared with normal control $(p \leq 0.001)$ but increased significantly in MMV + Al-treated rats $(p \leq$ 0.001) when compared with the Al-treated group. On the other hand, there was no significant $(p \leq 0.001)$ alteration of DNA and RNA levels in rats treated with MMV alone.

The level of acetyl cholinesterase decreased significantly $(p \leq 0.001)$ in the plasma, brain, cerebral cortex and hippocampus of Altreated rats (Figure 5). However, the enzyme level increased following co-administration of $M M V$ and $\mathrm{AlCl}_{3}(\mathrm{p} \leq 0.001)$.

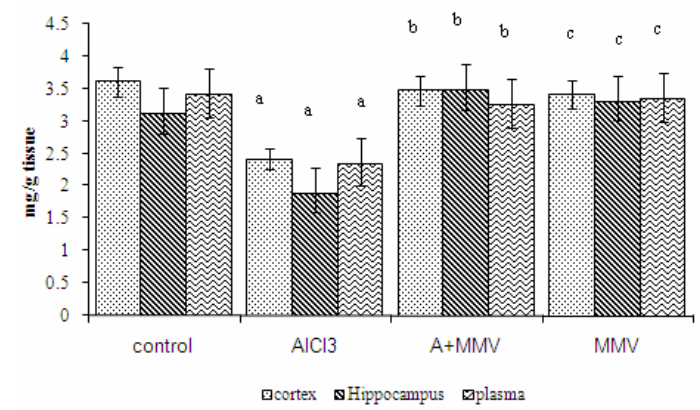

Figure 3: Effect of $M M V$ on DNA content (mean \pm SEM) in of plasma, cerebral cortex and hippocampus of Al- treated rats. ${ }^{a} p \leq 0.001, \mathrm{AlCl}_{3}$ group compared with control group; ${ }^{b} p \leq 0.001$, $M M V+\mathrm{AlCl}_{3}$ group compared with aluminiumtreated group; ${ }^{c}$ not significant $(p \leq 0.001) M M V$ treated group versus control

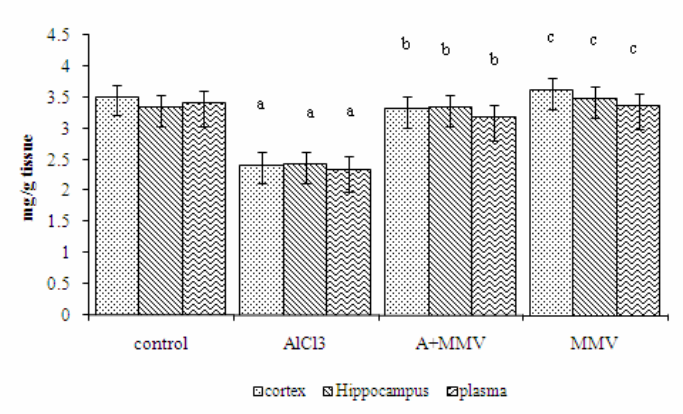

Figure 4: Effect of $M M V$ on RNA contents (mean \pm SEM) of cerebral cortex and hippocampus of Altreated rats. ${ }^{a} p \leq 0.001, \mathrm{AlCl}_{3}$ group compared with control group; ${ }^{\mathrm{b}} \mathrm{p} \leq 0.001, \mathrm{MMV}+\mathrm{AlCl}_{3}$ group compared with aluminium-treated group; ${ }^{c}$ not significant $(p \leq 0.001) M M V$ treated group versus control

\section{Histological observations}

We observed normal cellular structure of hippocampus in normal control group which signifies normal working memory of the rats (Figure 6A). Gross histopathological changes, including heavy loss of cortical neurons, lacunae spaces (50 $\mu \mathrm{m}$ diameter), ghost cells and vacuolated cytoplasm were observed in Al-treated animals (Figure 6B). On the other hand, remarkable improvement was observed in the MMV + Al-treated group. (Figure 6C, D). 


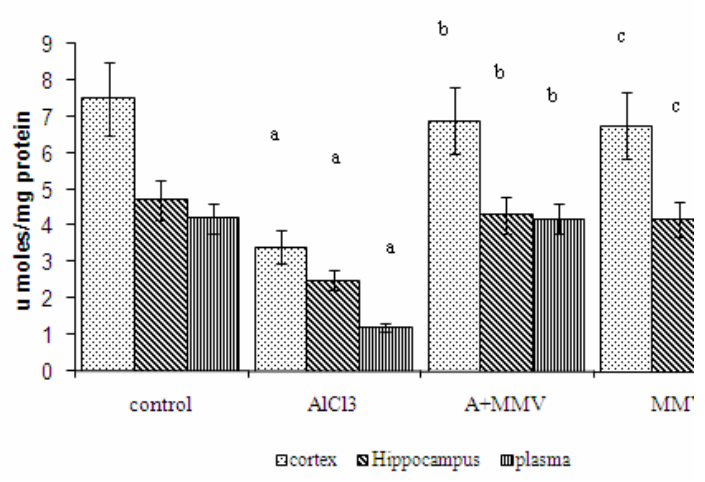

Figure 5: Acetyl cholinesterase (AChE) level (mean \pm SEM) in the plasma and brain of $M M V \mathrm{t}$ treated and Al- exposed rats. ${ }^{a} p \leq 0.001$, by Newman-Keuls multiple comparison test; $\mathrm{AlCl}_{3}(\mathrm{~A})$ group was compared with control group; ${ }^{b} \mathrm{p} \leq$ 0.001 , by Newman-Keuls multiple comparison test; $\mathrm{MMV}+\mathrm{AlCl}_{3}$ group was compared with aluminiumtreated group; c - non-significant (ns) control vs $M M V$ treated group.
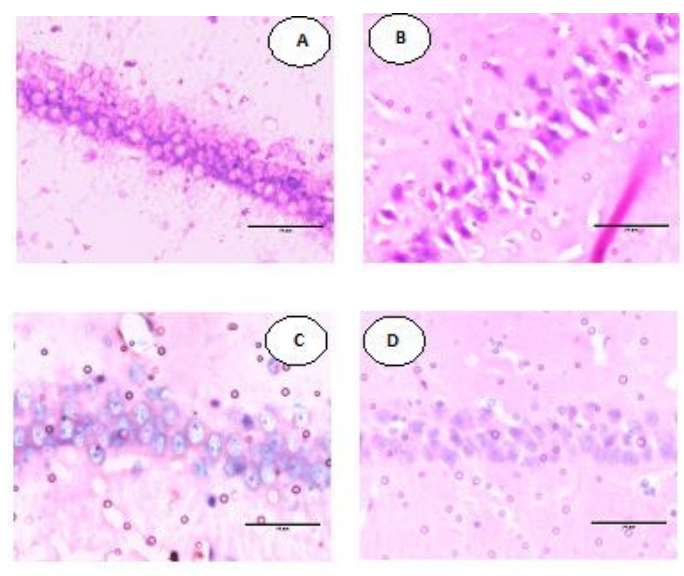

Figure 6: Microphotographs showing histopathological alterations in the hippocampus region of (A) control group, (B) Al-treated group $(100 \mathrm{mg} / \mathrm{kg}),(C)$ Al-treated $(100 \mathrm{mg} / \mathrm{kg})+\mathrm{MMV}$ (100 mg/kg) group, (D) MMV-treated (100 mg/kg) group

\section{DISCUSSION}

The animals treated with Al revealed altered behavioral changes within 90 days, suggesting a link between chronic Al-induced toxicity and the parameters evaluated. There was long-term memory impaired performance under the influence of $\mathrm{Al}$ exposure. The animals spent a shorter time in the arms of the test apparatus after exposure to $\mathrm{Al}$, thus depicting increased anxiety levels [11]. Reentry frequency of the animals increased, indicating disturbed cognitive behavior. This observation was also supported by histopathological findings in that $\mathrm{Al}$ treatment caused marked alterations such as heavy loss of cortical neurons, lacunae spaces (50 $\mu \mathrm{m}$ diameter), ghost cells and vacuolated cytoplasm. On the other hand, animals treated with MMV significantly showed improvement in cognitive function and longterm memory.

Following $\mathrm{Al}$ exposure, MMV treatment facilitated easy identification of previously visited arms and this may be due to correction in cholinergic neurotransmission, which in turn can be linked to altered memory function. Bhalla et al [12] reported the mechanism of action of Al induced toxicity and indicated that it causes defect in cognitive function. Levesque et al [13] observed severely damaged glia cells in rat brain following Al treatment. Hippocampus and cerebral cortex are the key structures of memory formation. Since the hippocampus is especially indispensable in the integration of spatial information, a decline in learning ability may be induced by the deterioration of hippocampal function [23].

Hu et al [14] has reported that Al-associated toxicity diminished motor activities and grip strength. Thus, improvement in a neurotransmitter enzyme such as AChE, and nuclear materials in rat blood and brain could be responsible for the improvement in learning, memory, cognition and locomotor functions. The importance of neurobehavioral studies in risk assessment lies in the fact that behavior can be regarded as the net output of the sensory, motor and cognitive functions occurring in the nervous system and can serve as potentially sensitive end-points of chemically-induced neurotoxicity.

The increasing preparation and storage of food in Al vessels, cans, and foils may 
increase the Al content, particularly in food that are salty, acidic, or alkaline. There has been insufficient concern about toxic consequences of $\mathrm{Al}$ ingestion because its bioavailability was considered to be poor and the gastrointestinal tract normally represented a barrier to $\mathrm{Al}$ absorption under normal circumstances but this barrier can be breached. It has been shown that individuals ingesting large amounts of $\mathrm{Al}$ compounds do absorb significant amounts resulting in elevated plasma levels [15].

Al-exposed rats showed increased blood glucose level which may be due to decreased pyruate formation that affects the synthesis of acetylcholine. It appears that Al toxic potency, which leads to alteration in acetylcholine level, might have caused neurobehavioral changes. Davis [16] has observed that acetyl choline affects human memory and cognitive function by dramatically decreasing the activity of acetylcholine tranferase in the cortex and hippocampus of Alzheimer patients.

Increase in blood glucose level may have disrupted carbohydrate metabolism due to enhanced breakdown of liver glycogen, possibly mediated by increase in adrenocorticotrophic and glucagon hormones and/or reduced insulin activity [17]. Sallam et al [18] reported that $\mathrm{Al}$ accumulation in the liver leads to liver damage as a result of increased enzymes levels of ALP, SGOT, SGPT and glucose in the serum. Increased enzyme levels may cause cellular degeneration or destruction of hepatic cells. Decreased plasma concentration of ALP, SGOT, SGPT and glucose levels in MMVtreated animals suggests that the drug exhibits hepato-protective activity.

Aluminium is a trivalent cation and has high affinity for negatively charged groups such as phosphates which are present in nucleic acids and phospharelated proteins. Although plasma and brain tissue DNA and RNA levels of Al-exposed rats decreased, MMV-treated rats had these levels restored, thereby showing a positive influence of the plant extract on either degradation or synthesis of nucleic acids in these animals.

Al causes disturbances in cholinergic neurotransmission and disrupts the cognitive behavior of animals by increasing the stress levels. Studies have shown that Al exposure results in a decrease in hexokinase activity [19], which in turn decreases the pyruvate formation and hence affect the synthesis of acetylcholine and subsequently the enzyme activity of AChE. Kowall et al [20] found that $\mathrm{Al}$ is a pro-oxidant and indirectly results in the production of free radicals leading to oxidative damage and reduced levels of reactive oxygen species (ROS) which indirectly affects acetyl cholinesterase enzyme activity.

In our earlier study, increased peroxidative damage of lipids and proteins in cells was observed after $\mathrm{Al}$ exposure in rats [21]. On the other hand, MMV-treated rats decreased LPO level after drug treatment suggesting that MMV can protect against peroxidative damage. Since oxidative damage is mediated by free radicals, it was necessary to investigate the status of endogenous antioxidant enzymes under the different treatment conditions. The results revealed that tissue damage was prevented by MMV and this may be due to the presence of active molecules such as saponin and flavanoids [4] which are well known antioxidants.

An enzyme, such as SOD, is an important antioxidant, which protects the brain from peroxidase- mediated neuronal damage, and therefore, decreased level of these biomolecules, may lead to increased severity of $\mathrm{Al}$ toxicosis in the brain. It was observed that in $\mathrm{Al}$ intoxication, the activity of antioxidant enzyme such as SOD was significantly increased compared to control. Usually, decreased antioxidant to oxidant ratio plays a crucial role in generating a condition of oxidative stress. The decreased activity might have resulted from oxidative modification of proteins. Our previous study showed significantly decreased activity of 
SOD in MMV + Al-treated group; therefore, in this experimental condition, SOD may be responsible for preventing the tissues from oxidative damage [21]. Evidence for stronger glia activation has been observed in Alexposed animals and this is claimed to be responsible for pathological and inflammatory events [23]. Inflammatory responses are known to play an important role in neurodegenerative disease such as Alzheimer's disease (AD).

Gross disruption in brain cells was seen during microscopical examination following Al treatments, which indicate adverse effects at sub-cellular levels including changes in the structure of the cerebral cortex due to loss of neurons, ghost cells and gliosis. StruysPonsar et al [22] also found that Al causes structural changes in the cerebral cortex due to loss of neurons, ghost cells, gliosis, hippocampus and cortex, and this may affect the various enzymes responsible for synthesis as well as degradation of neurotransmitters [19].

\section{CONCLUSION}

MMV has a protective effect on the levels of various biochemical and neurochemical parameters in blood and brain. It can also protect against cognitive impairment during chemically-induced stress conditions caused by metals such as aluminium chloride. Thus, MMV is promising for the treatment of cognitive impairment in neurodegenerative disorders.

\section{ACKNOWLEDGEMENT}

The authors are thankful to SASTRA University and ICMR, New Delhi for providing financial assistance. We also thank Dr. M. Micheal Aruldhas, Head of Department of Endocrinology, University of Madras, India for his invaluable support.

\section{REFERENCES}

1. Abbasali KM, Zhila T, Farshad N. Developmental Toxicity of Aluminium from High doses of A/C/3 in Mice. J Appl Res. 2005; 5: 575-579.

2. Strong MJ, Garruto RM, Joshi JG, Mundy WR, Shafer TJ. Can the mechanisms of aluminium neurotoxicity be integrated into a unified scheme? J Toxicol. Environment Health 1996; 48 (6): 599-613.

3. Ochmanski W, Barabasz W. Aluminium-occurrence and toxicity for organisms of rat fetuses and sucklings. Brain Res Bull 2000; 55: 229-234.

4.. Thirunavukkarasu SV, Venkataraman S, Lokesh Upadhyay. In vitro antioxidant and antibacterial activity of Polyherbal Manasamitra vatakam (MMV) drug. J Pharmacy Res 2010; 3(8): 2042 -2047.

5. Chattopadhyay RR. Possible mechanism of hepatoprotective activity of Azadirachta indica leaf extract: part II. J Ethnopharmacol 2003; 89: 217-219.

6. Kulkarni SK. Handbook of Experimental Pharmacology, 3rd edn. Vallabh. Prakashan, Delhi, 1999.

7. Paxinos G, Watson C. The Rat Brain in Stereotaxic Coordinates. Academic Press, New York 1982.

8. Sambrook, J, Fritsch EF. Maniatis T. Extraction and isolation of nucleic acids (DNA and RNA) from mammalian cells. In: Molecular Cloning. Alaboratory Manual. Sambrook, J., Fritsch, E.F. and Maniatis, T. (eds.). 2nd ed. Chapter 1, Cold Spring Harber Laboratory Press., 1989; pp 15-45.

9. Ellman GL, Courtney DK, Andres V, Featherstone RM. A new and rapid colorimetric determination of acetylcholinestrase activity. Biochem Pharmacol 1961; 7: 88-95.

10. Nakayama $H$, Ginsberg $M D$, Dietrich WD. (S)Emopamil, a novel calcium channel blocker and serotonin S2 antagonist, markedly reduces infarct size following middle cerebral artery occlusion in rat. Neurology 1988; 38: 1667-1673.

11. Elliott JM, Heal DJ, Marsden CA. Experimental Approaches to Anxiety and Depression. Chichester New York: John Wiley, 1992.

12. Bhalla P, Garg ML, Dhawan DK. Protective role of lithium during aluminium induced neurotoxicity. Neuro Inter 2010; 56: 256-262.

13. Levesque L, Mizzen CA, McLachlan DR, Fraser PE. Ligand specific effects on aluminium incorporation and toxicity in neurons and astrocytes. Brain Res 2000; 877: 191-202.

14. Hu $H$, Yang YJ, Li XP, Chen GH. Effect of aluminum chloride on motor activity and species-typical behaviors in mice. Zhonghua Lao Dong Wei Sheng Zhi Ye Bing Za Zhi 2005; 23(2): 132135.

15. Alfrey AC. Gastrointestinal absorption of aluminum. Clin Nephro, 1985; 24:84-87. 
16. Davies P. Neurotransmitter-related enzyme in dementia of Alzheimer's type. Brain Res 1990; 171: 319-327.

17. Raja M, Al-Fatah A, Ali M, Afzal $M$, Hassan RA, Menon M, Dhami MS. Modification of liver and serum enzymes by paraquat treatment in rabbits. Drug Metabolism. Drug Inter 1992; 10: 279-291.

18. Sallam SMA, Nasser MEA, Yousef MSH, El- Morsy, Mahmoud, Yousef MI. Influence of aluminium chloride and ascorbic acid on performance, Digestability, Caecal microbial activity and biochemical parameters of rabbits. Res $J$ Agricultural Biological Sci 2005; 1(1): 10-16.

19. Nehru B, Bhalla $P$, Garg $A$. Evidence for centrophenoxine as a protective drug in aluminium induced behavioral and biochemical alteration in rat brain. Mol Cell Biochem 2006; 290(1-2): 33-42.

20. Kowall NW, Pendlebury WW, Kesler JB, Perl DP, Beal MF. Aluminium-induced neurofibrillary degeneration affects a subset of neurons in rabbit cerebral cortex, basal forebrain and upper brainstem. Neuroscience 1989; 29: 329-377.

21. Thirunavukkarasu SV, Venketaraman S, Upadhyay L. Ameliorating effect an ayurvedic herbo mineral preparation in $\mathrm{AlCl}_{3}$ induced cognitive dysfunction in rats. Biomedicine 2010; 30: 40 47.

22. Struys-Ponsar C, Florence $A$, Gauthier $R$, Crichton $R$, van den Bosch de Aguilar $P$. Ultra structural changes in brain parenchyma during normal aging and in animal models of aging. $J$ Neural Transmision 1994; 44: 111-132.

23. Platt B, Fiddler G, Riedel G, Henderson Z. Aluminium toxicity in the rat brain:histochemical and immunocytochemical evidence. Brain Res. Bull, 2001; 55: 257-267. 